\title{
FATIGUE LIFE AND MICROSTRUCTURE AFTER MULTIPLE REMELTING OF A359 MATRIX COMPOSITES REINFORCED WITH SIC PARTICLES
}

\begin{abstract}
The article presents the results of fatigue life tests and microstructure examinations of A359 alloy matrix composites (F3S.10S and F3S.30S) containing 10 and $30 \mathrm{wt} \%$ of SiC particles, subjected to multiple remelting by conventional gravity casting. Mechanical characteristics were determined in a modified low cycle fatigue (MLCF) test, enabling rapid estimation of fatigue life and other mechanical parameters in practice of any material. Qualitative and quantitative metallographic examinations were also carried out. The quantitative evaluation of microstructure was performed by computer image analysis. A set of geometrical parameters of the reinforcing particles, pores and eutectic precipitates present in the metal matrix was determined. The relationships between the mechanical parameters, structural characteristics and the number of remelting operations were presented. It was found that up to the fourth remelting, the mechanical characteristics, including fatigue life, are slightly deteriorated but decrease gradually in the subsequent operations of remelting. The observed effect is mainly due to the shrinkage porosity occurring as a result of gravity casting. To eliminate this defect, the use of squeeze casting process was recommended. It has also been shown that multiple remelting can be an easy and economically well-founded alternative to other more expensive recycling methods.
\end{abstract}

Keywords: alloy, composite, microstructure, properties, recycling.

\section{Introduction}

In the group of attractive engineering materials, various composites, including those based on metal matrix, occupy an important place. For many years, particular interest has been focused on metal matrix composites based on light metal alloys, mainly due to their low weight and high level of performance properties which, compared to other alloys, made them very popular and opened the way for their potential use in industry, e.g. automotive or aerospace [1].

On the other hand, with the constantly growing volume of produced materials or ready products, an increase in the amount of produced waste has also been observed. In accordance with the EU requirements, there is a need for recycling carried out in such a way as to obtain full-fledged re-materials or products. That is why so much attention is paid to the methods of recycling. It should be noted that in the case of metal matrix composites, various methods of recycling are usually used [2], but nearly all of them are expensive and demanding at least a two-step procedure.

Based on previous own studies [2-4] concerning A359 matrix composites bulk reinforced with $\mathrm{SiC}$ or $\mathrm{Al}_{2} \mathrm{O}_{3}$ particles it was possible to demonstrate that they can be successfully recycled also by means of direct multiple remelting [2-4]. The influence of this process, carried out by conventional gravity casting, on the mechanical properties examined in static tensile test, resistance to friction wear, damping capacity, a series of physical properties such as density, electrical conductivity, thermal expansion coefficient, etc. was presented. It was demonstrated that up to the fourth remelting the functional properties are slightly deteriorated, to decrease later slowly with the subsequent remelting operations [2].

In this article, the effect of multiple remelting of the A359 matrix composites (F3S.10S and F3S.30S) bulk reinforced with $\mathrm{SiC}$ particles (10 $\mathrm{wt} \%$ and $30 \mathrm{wt} \%$ ) was examined in terms of the resulting fatigue life of the composites.

After repeated remelting, the quality of castings was examined by $\mathrm{X}$-rays to eliminate castings with defects. To assess the fatigue life, the original modified low cycle test (further referred to as MLCF) was used [5-7]. In the authors' opinion, this test can be used as a method for the rapid estimation of fatigue parameters. The microstructure was described both qualitatively and quantitatively using a set of geometric parameters of its individual constituents.

\section{Test material}

When selecting the test material, two requirements were taken into account, i.e. the restrictions imposed on the content of $\mathrm{Si}$ in the metal matrix of the composites bulk reinforced with $\mathrm{SiC}$ particles and the required temperature regimes [8-10] (Fig. 1).

\footnotetext{
* MOTOR TRANSPORT INSTITUTE, 80 JAGIELLOŃSKA STR., 03-301 WARSAW, POLAND

** AGH UNIVERSITY OF SCIENCE AND TECHNOLOGY, FACULTY OF FOUNDRY ENGINEERING DEPARTMENT OF FOUNDRY PROCESS ENGINEERING, AL.A.MICKIEWICZA 30, 30-059 KRAKÓW, POLAND

*** INSTITUTE OF PRECISION MECHANICS, 3 DUCHNICKA STR., 01-796 WARSAW, POLAND

**** FOUNDRY RESEARCH INSTITUTE, 73 ZAKOPIAŃSKA STR., 30-418 CRACOW, POLAND

* Corresponding author: mmaj@agh.edu.pl
} 
It should be underlined that too low $\mathrm{Si}$ content leads to disadvantageous reactions at the reinforcement/matrix interface with the subsequent formation of $\mathrm{Al}_{4} \mathrm{C}_{3}$, which is the compound whose presence causes a significant degradation of the mechanical parameters.

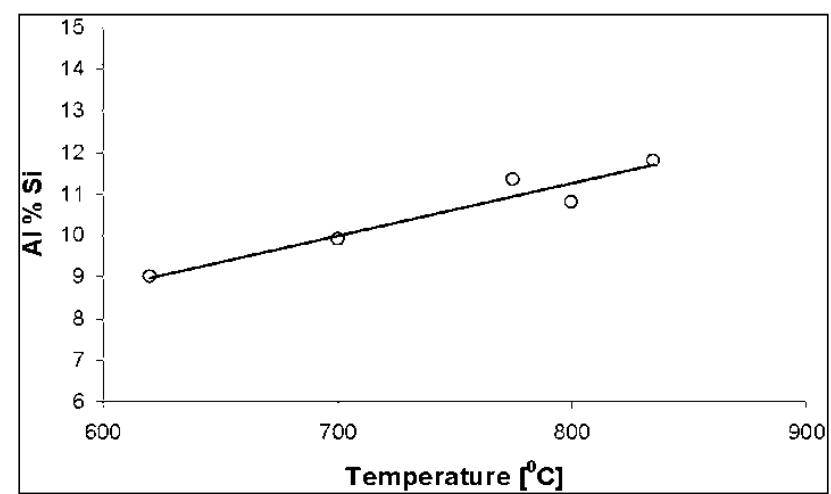

a)

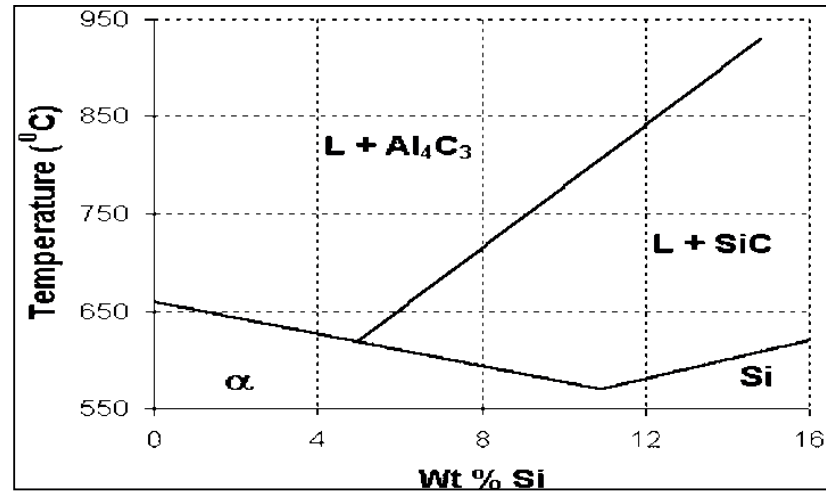

b)

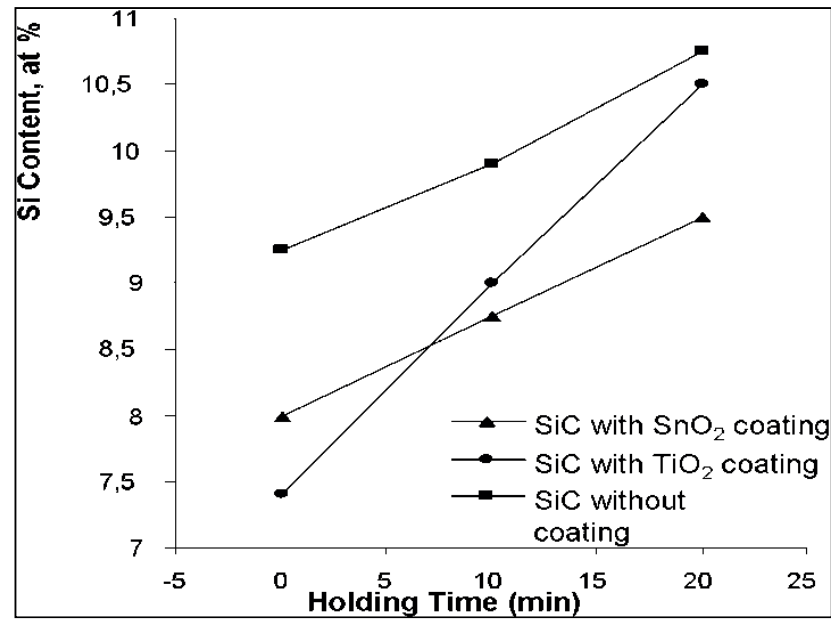

c)

Fig. 1. Conditions of $\mathrm{Al}_{4} \mathrm{C}_{3}$ formation: (a) the required $\mathrm{Si}$ content in the matrix of $\mathrm{SiC}$ reinforced composites preventing the $\mathrm{Al}_{4} \mathrm{C}_{3}$ formation at different temperatures [8]; (b) the stability area of $\mathrm{SiC}$ depending on the Si content and casting temperature [9], and (c) barrier oxide coatings on $\mathrm{SiC}$ inhibiting the $\mathrm{Al}_{4} \mathrm{C}_{3}$ formation [10]

\section{Mechanical properties}

To estimate fatigue life, a modified low cycle fatigue test (MLCF) was used [8-10]. This test enables the determination of parameters which result from the Manson-Coffin-Morrow relationships:

$$
\sigma_{\mathrm{a}}=\mathrm{K}^{\prime}\left(\varepsilon_{\mathrm{p}}\right)^{\mathrm{n}}
$$

$$
\sigma_{\mathrm{a}}=\sigma_{\mathrm{f}}^{\prime}\left(2 \mathrm{~N}_{\mathrm{f}}\right)^{\mathrm{b}}
$$

$$
\varepsilon_{\mathrm{p}}=\varepsilon_{\mathrm{f}}^{\prime}\left(2 \mathrm{~N}_{\mathrm{f}}\right)^{\mathrm{c}}
$$

\begin{tabular}{|c|c|c|}
\hline$\sigma_{\mathrm{a}}$ & - & amplitude of cycle stress, \\
\hline$\sigma_{\mathrm{f}}^{\prime}$ & - & $\begin{array}{l}\text { „stress coefficient" roughly equal to the } \\
\text { ultimate tensile strength (UTS), }\end{array}$ \\
\hline$\varepsilon_{\mathrm{f}}$ & - & true plastic strain caused by stress $\sigma_{\mathrm{f}}$ \\
\hline $2 \mathrm{~N}_{\mathrm{f}}$ & - & number of load cycles to sample failure, \\
\hline & - & $\begin{array}{l}\text { plastic strain (the true strain caused by } 2 \mathrm{~N}_{\mathrm{f}} \\
\text { load cycles), }\end{array}$ \\
\hline & - & cyclic strength coefficient, \\
\hline & - & $\begin{array}{l}\text { strain hardening exponent under cyclically } \\
\text { varying loads, }\end{array}$ \\
\hline & & fatigue ductility exponent [4-7]. \\
\hline
\end{tabular}

where:

The fatigue strength necessary for the calculation of equations (1), (2) and (3), in the case of the MLCF method is assessed from an experimental graph (Fig. 2), which has been plotted as a result of long-lasting experiments and is valid for a group of various engineering materials, including pure metals as well as ferrous and non-ferrous metal alloys [4-7].

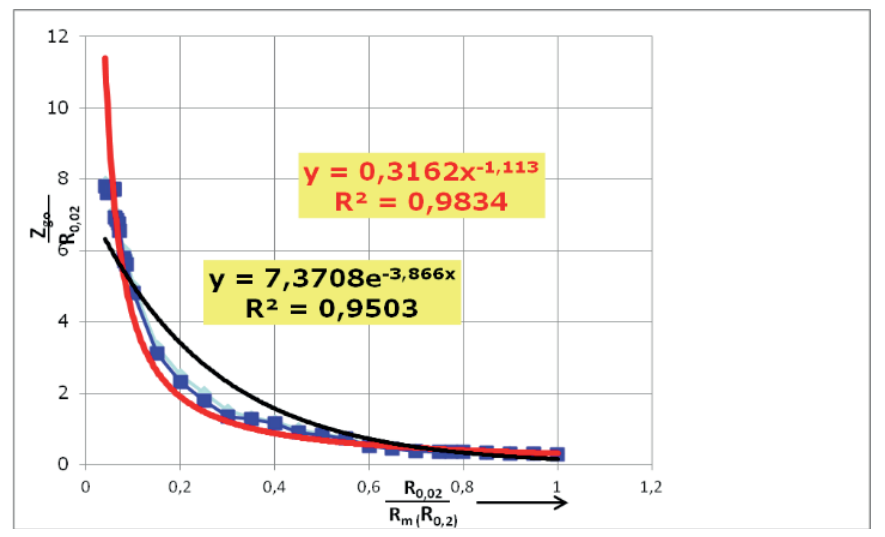

Fig. 2. Experimental curve to evaluate the fatigue life of various materials $[8,9,10]$

The determination of $\mathrm{b}, \mathrm{c}, \mathrm{n}$ ' and $\mathrm{K}$, as well as $\varepsilon_{\max }$ is possible owing to the following guidelines adopted in the studies [4-7] one-sided cycles are applied during tension in fatigue test to eliminate the risk of specimen buckling, the permanent deformations occurring in the case of a preset low number of cycles are characterized by similar dependence on the cycle amplitude as the deformation which occurs in the sample upon its failure [4-7], all tested mechanical properties are determined on one sample only, the run of the straight lines based on equations (2) and (3) plotted in a double logarithmic scale is determined by the position of points with the following coordinates: [ $\operatorname{Ln} 20 \ln \mathrm{R}_{\mathrm{m}}$ ] and [ $\ln \left(2 \mathrm{~N}_{\mathrm{f}}\right)$, $\ln \left(\mathrm{Z}_{\mathrm{go}}\right)$ ]: equation (2), and $\left[\ln 20, \ln \varepsilon_{f}\right]$ and $\left[\ln \left(2 N_{f}\right), \ln \varepsilon z\right]$ : equation (3), for 
the assessment of fatigue life during rotational bending an experimental graph shown in Figure 2 is used [4-7].

The accommodation limit $\left(\mathrm{R}_{\mathrm{a}}\right)$ defined as stress above which the permanent deformation is not stabilized and $\mathrm{R}_{0,2}$ defined as the yield point were included into the range of the above mentioned mechanical parameters, examined on a single specimen only. This is very important because all the static mechanical parameters and those which are responsible for the low cycle fatigue allow for very precise characterization of the examined material irrespective of the degree of its heterogeneity. Examples of the stress-strain relationship recorded during cycling of A359 alloy specimens [4] and specimens of F3S.10S, F3S.20S [4] and F3S.30S composites are shown in Figure 3.

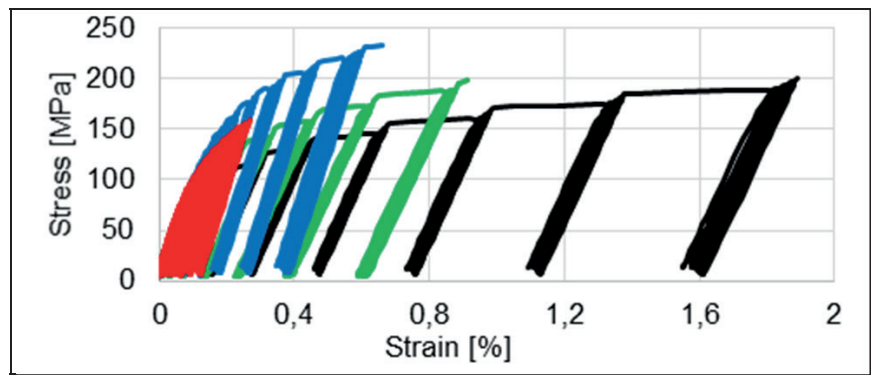

- A359 [4] - F3S.10S - F3S.20S [4] - F3S.30S

Fig. 3. Stress-strain relationship during cycling of specimens according to the methodology described in [5-7]

The diagram in Fig. 3 shows that the highest stress was achieved for the F3S.20S composite [4] and the lowest - for the F3S.30S composite. These curves also illustrate the effect of sample cycling, where from it follows and is hardly surprising that A359 alloy is most susceptible to deformation and F3S.30S composite with the highest content of reinforcement (30 wt $\%$ $\mathrm{SiC}$ ) is most brittle.

The mechanical parameters determined during the MLCF test as a function of the number of remelts for both F3S.10S and F3S.30S composites are presented in Figs 4 and 5 , respectively.

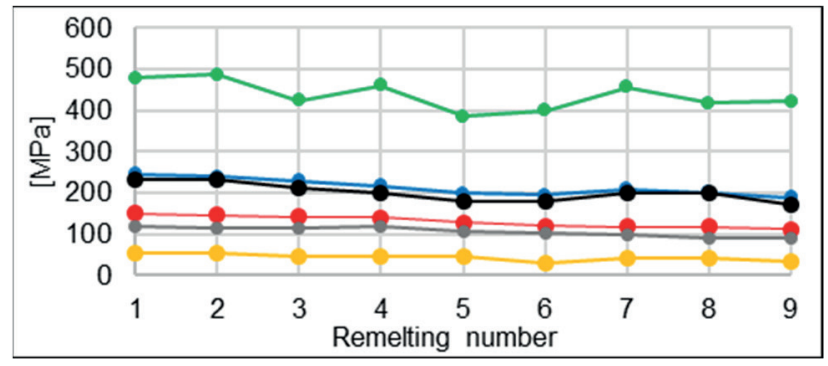

a

$-\bullet-U T S-\bullet-R_{0,05}-\bullet-R_{0,2}-\bullet-Z_{\text {go }}-\bullet-R_{a}-\bullet-K^{\prime}$

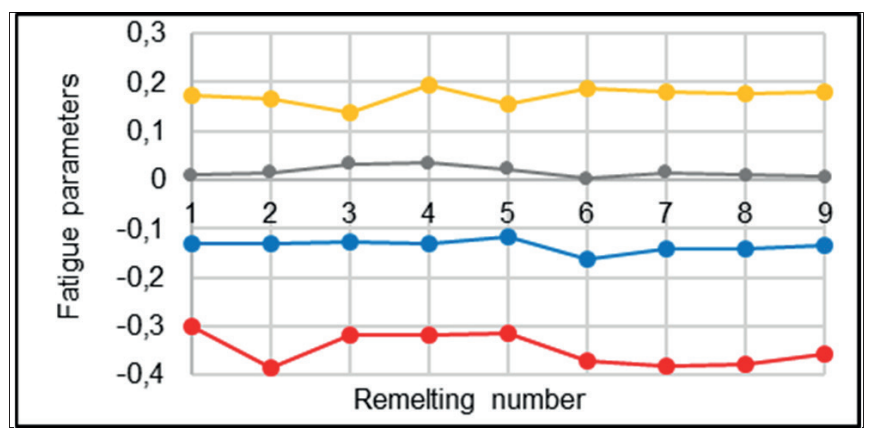

b

$$
-\bullet-b-\bullet-c-\bullet-\varepsilon \max -\bullet-n^{\prime}
$$

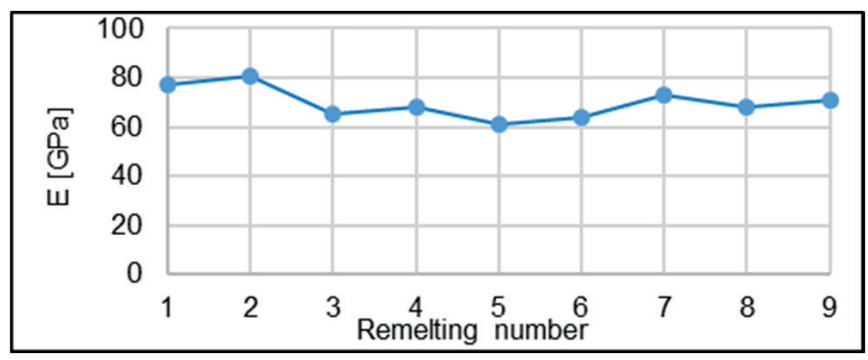

c

$-\bullet-\mathrm{E}$

Fig. 4 Mechanical parameters of the F3S.10S composite vs number of remelts:

a) $R_{m}$ - ultimate tensile strength; $R_{0,05}$-stress limit; $R_{0,2}$-yield point; $Z_{g o}$ - assessed fatigue life; $R_{a}$ - accomodation limit; $K^{\prime}$ - stress coefficient under cyclically varying loads; $b$ ) $b$ - Basquin's coefficient; $c$ - fatigue ductility exponent; $\varepsilon_{\max }-$ maximum allowable strain; n' - strain hardening exponent under cyclically varying loads, c) E - Young's modulus

The courses of the curves (Fig. 4a) plotted for the F3S.10S composite prove that up to the fourth remelting, most of the determined mechanical parameters slightly decrease and continue decreasing when more remelts follow. Only the values of the stress coefficient under cyclically varying loads $\left(\mathrm{K}^{\prime}\right)$ presented in Fig. 4a, the fatigue ductility exponent (c) shown in Fig. 4b and Young's modulus (E) shown in Fig. 4c are characterized by larger fluctuations.

The courses of the curves shown in Fig. 5a-c plotted for the F3S.30S composite show that up to the fourth remelting, the determined mechanical parameters of the composite slightly decrease and continue decreasing as in the case of F3S.10S composite when more remelts follow. Only the values of the stress coefficient under cyclically varying loads (K') are characterized by larger fluctuations (Fig. 5a); other fatigue parameters practically remain at the same level up to the ninth remelting. 


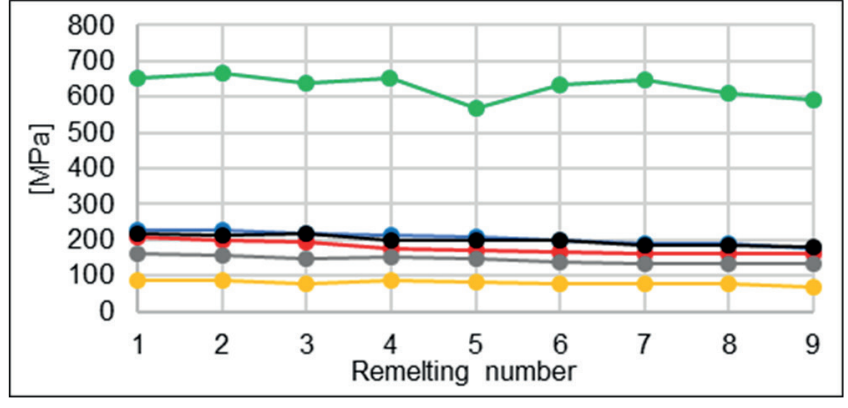

a

$-\bullet-U T S-\bullet-R_{0,05}-\bullet-R_{0,2}-\bullet-Z_{\mathrm{go}}-\bullet-\mathrm{R}_{\mathrm{a}}-\bullet-\mathrm{K}^{\prime}$

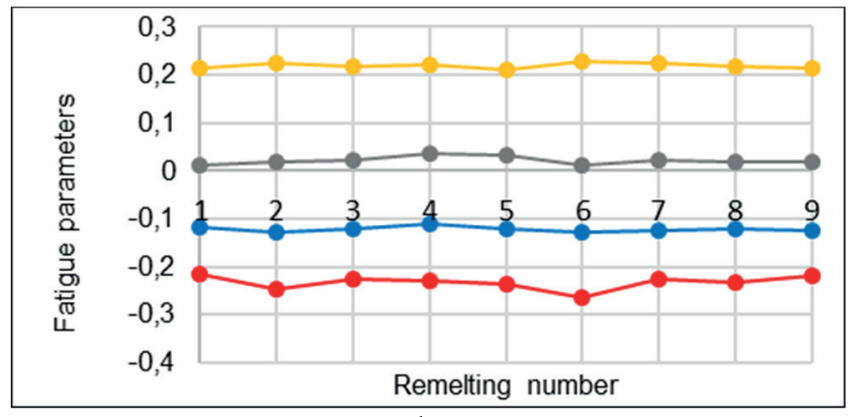

b

$$
-\bullet-\mathrm{b}-\bullet-\mathrm{c}-\bullet-\varepsilon_{\max }-\bullet-\mathrm{n}^{\prime}
$$

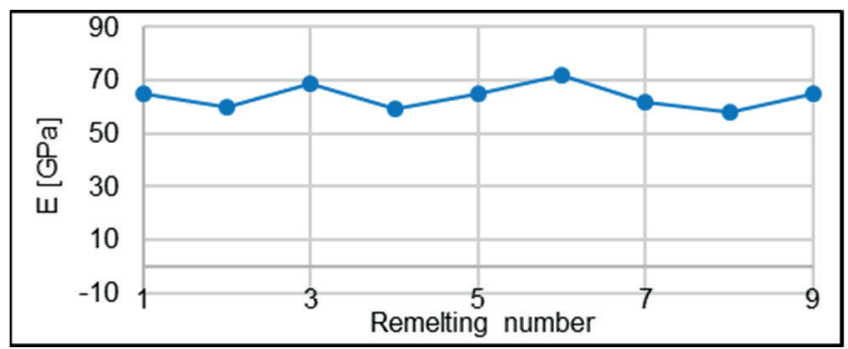

c

- $-\mathrm{E}$

Fig. 5 Mechanical parameters of the F3S.30S composite vs number of remelts:

a) $R_{m}$ - ultimate tensile strength; $R_{0,05}-$ stress limit; $R_{0,2}$ - yield point; $Z_{\mathrm{go}}$ - assessed fatigue life; $\mathrm{R}_{\mathrm{a}}$ - accomodation limit; $\mathrm{K}$ 'stress coefficient under cyclically varying loads; b) b - Basquin's coefficient; $\mathrm{c}$ - fatigue ductility exponent; $\varepsilon_{\max }$ - maximum allowable strain; n' - strain hardening exponent under cyclically varying loads, c) E - Young's modulus

\section{Microstructure}

Examples of the microstructures of the F3S.10S and F3S.30S composites after the first and the ninth remelting are shown in Figs. 6 and 7. Figure 6 shows the microstructure of the F3S.10S composite, while Figure 7 shows the microstructure of the F3S.30S composite. It should be underlined that the images shown in these pictures are of an illustrative character only and as such should not be interpreted quantitatively.

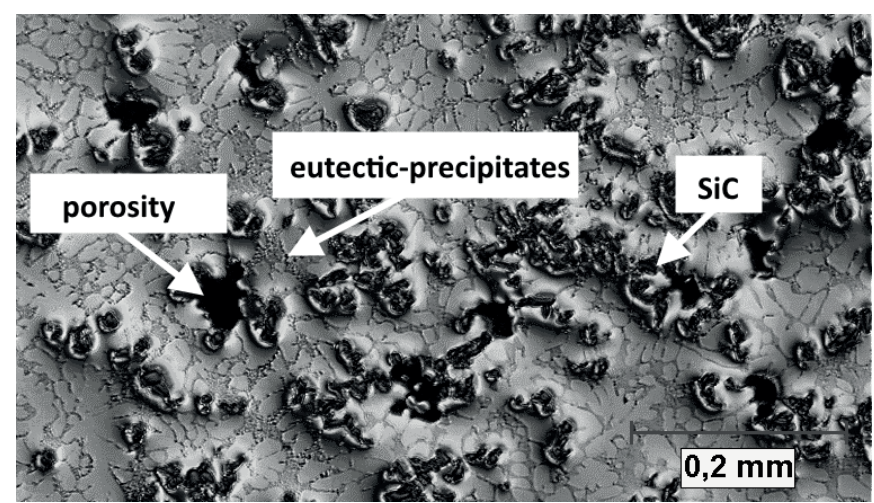

F3S.10S composite - the first remelting

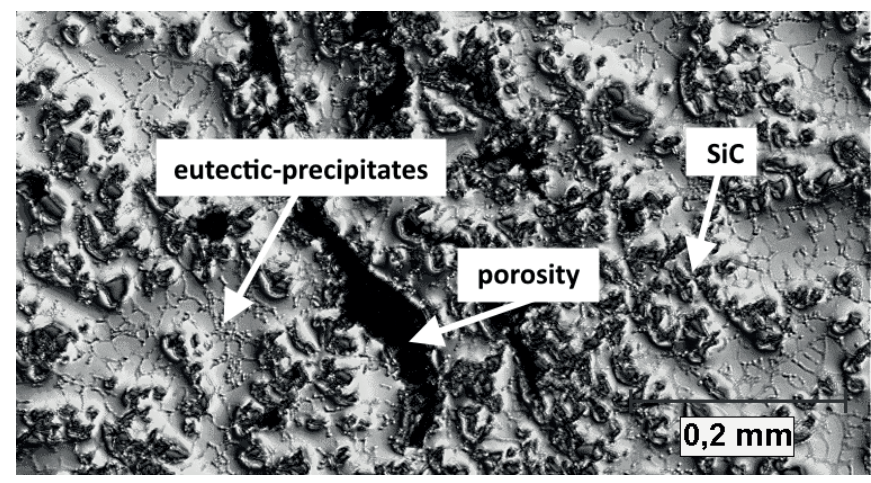

F3S.10S composite - the ninth remelting

Fig. 6. The microstructure of F3S.10S composite after the first and ninth remelting, phase contrast, magn. 100x

Due to the fact that the successive remelting operations were done by the technique of conventional gravity casting, the microstructure of both tested composites showed the tendency to the formation of shrinkage porosity. Especially after the ninth remelting, the locally occurring pores of a relatively large size were identified. However, it should be pointed out that photographs of the microstructures were taken using the maximum criterion characterized by the worst field of view. Therefore, only the results of quantitative metallographic examinations can be used as a basis for interpretation.

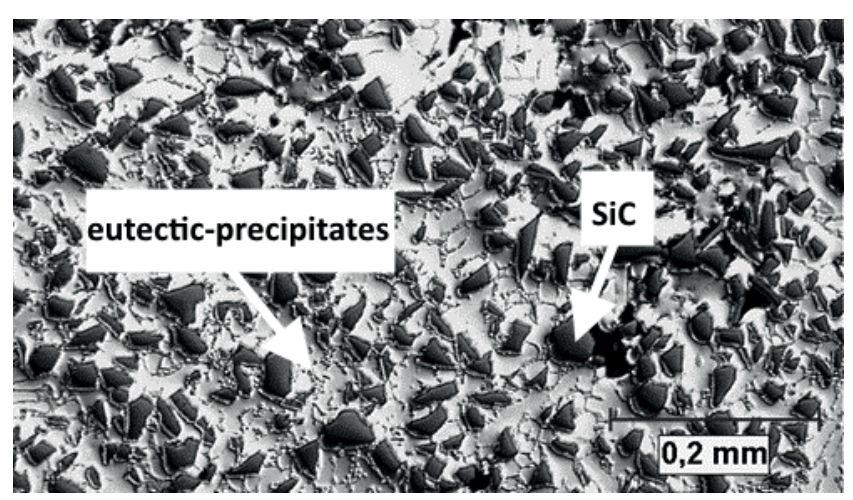

F3S.30S composite - the first remelting 


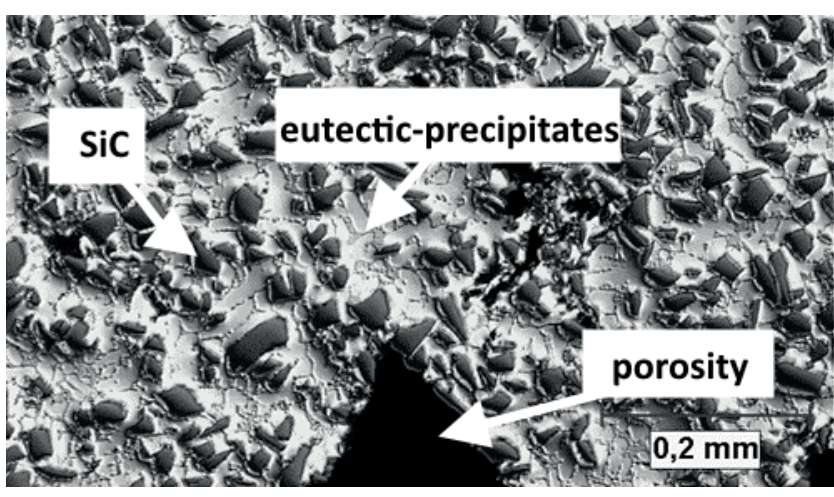

F3S.30S composite - the ninth remelting

Fig. 7. The microstructure of F3S.30S composite after the first and ninth remelting, phase contrast, magn. 100x

The set of geometrical parameters of the eutectic precipitates occurring in metal matrix, of the $\mathrm{SiC}$ reinforcing particles and pores was determined by image analysis. As a result of this analysis, the mean free distance $(\lambda)$ between the above mentioned microstructure elements was recognized as the most important factor. This parameter linked by the relationship $\lambda=\left(1-\mathrm{V}_{\mathrm{V}}\right) / \mathrm{N}_{\mathrm{L}}$ results from the volume fraction $\left(\mathrm{V}_{\mathrm{v}}\right)$ of the measured elements and from the estimation of their relative areas $\left(\mathrm{N}_{\mathrm{L}}\right)$.

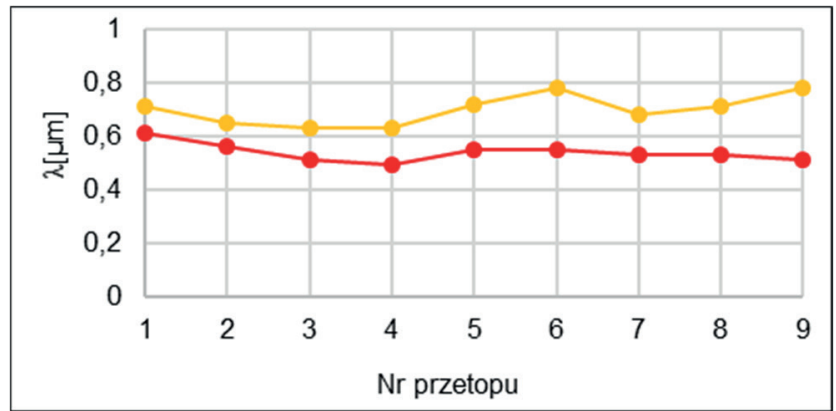

-๑ F3S.10S - - F3S.30S

Fig. 8. The distribution of eutectic precipitates in the tested composites depending on the number of remelting operations

The diagrams in Figs. 8-10 show the influence of the number of remelting operations but only on the parameter $\lambda$ defined as a mean free distance between the individual elements of the microstructure. It was found that the number of remelting operations practically did not affect the mean free distance between the eutectic precipitates $\left(\lambda_{\text {eut }}.\right)$, as shown in Fig. 8.

On the other hand, differences observed in the values of the mean free distance between the reinforcement particles $\left(\lambda_{\mathrm{SiC}}\right)$ were due to the tendency of these particles to form $\mathrm{SiC}$ aggregations. This tendency was much more pronounced and the aggregations were formed more easily when the content of $\mathrm{SiC}$ was low (Fig. 9). The result was a decrease in the $\lambda_{\mathrm{SiC}}$ value recorded with the growing number of remelting operations in the F3S.10S composite.
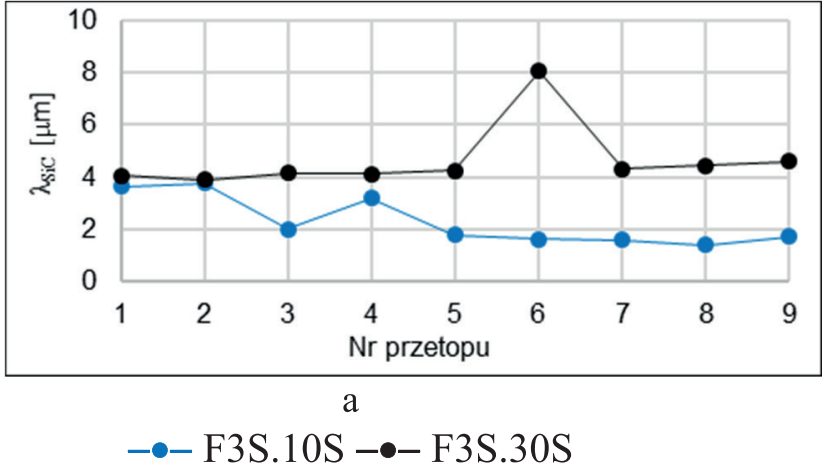

Fig. 9. The distribution of $\mathrm{SiC}$ particles in the tested composites depending on the number of remelting operations.

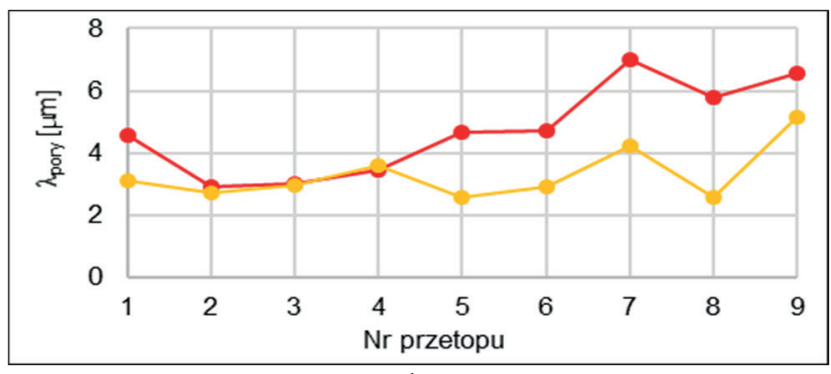

b

-•-F3S.10S -๑-F3S.30S

Fig. 10. The distribution of pores in the tested composites depending on the number of remelting operations

The differences observed in the values of the mean free distance between the pores $\left(\lambda_{\text {pores }}\right)$ are caused by the shrinkage porosity increasing with the increasing number of remelting operations (Fig. 10). This shrinkage porosity can be eliminated by the application of squeeze casting during remelting process.

\section{Conclusions}

Based on the studies of fatigue life using MLCF test and microstructure examinations of A359 matrix composites reinforced with $\mathrm{SiC}$ particles and subjected to multiple remelting it is possible to formulate the following concluding remarks:

- the number of remelting operations has no major impact on the distribution of eutectic precipitates in the composite matrix,

- the tendency of the reinforcing $\mathrm{SiC}$ particles to form aggregations increases with the decreasing content of $\mathrm{SiC}$ and with each next remelting operation,

- the distribution of pores controlled by the presence of shrinkage porosity increases with the increasing number of remelting operations, due to the simultaneous increase in the size and volume fraction of pores (lower value of $\mathrm{N}_{\mathrm{L}}$ and higher value of $\mathrm{V}_{\mathrm{V}}$ ),

- the observed structural changes are small enough to leave 
the mechanical characteristics unaffected,

- the positive research effect is connected with the absence of any undesired reactions at the composite reinforcement/ matrix interface,

- the usefulness of the proposed MLCF method in rapid assessment of fatigue life was proved,

- to prevent the occurrence of shrinkage porosity, the process of multiple remelting should be carried out by the squeeze casting method,

- the results of previous studies of the A359 alloy and F3S.20S composite as well as the results of the present studies have proved that the best properties are obtained in the F3S.20S composite,

- $\quad$ the multiple remelting of the examined composites may be an alternative to other more expensive methods of recycling.

\section{REFERENCES}

[1] J. Sobczak, Kompozyty metalowe 2001 Instytut Odlewnictwa i Instytut Transportu Samochodowego, Kraków-Warszawa.

[2] Klasik, J. Sobczak, K. Pietrzak, N. Sobczak, A. Wojciechowski, Influence of multiple remelting of particulate reinforced cast aluminum composites on their properties and structure, 2012
Warsaw-Cracow.

[3] K. Pietrzak, K. Makowska, J. Sobczak, A. Wojciechowski, D. Rudnik, Journal of Materials Eng. and Performance. 1-7 (2016), DOI: 10.1007/s11665-015-1870-x.

[4] K. Pietrzak, A. Klasik, M. Maj, J. Sobczak, A. Wojciechowski, Mechanik (2016), accepted for print.

[5] M. Maj, Zastosowanie zmodyfikowanej niskocyklowej próby zmęczeniowej do wyznaczania właściwości mechanicznych żeliwa ADI $\mathrm{w}$ temperaturze podwyższonej i pokojowej. Projekt badawczy nr 4 T08B 006 25, Kraków 2005.

[6] M. Maj, Trwałość zmęczeniowa wybranych stopów odlewniczych, 2012 Wyd. Archives of Foundry Engineering, Katowice-Gliwice.

[7] M. Maj, J. Piekło, Arch. of Metall. and Mater. 54 (2), 393-397 (2009).

[8] Labib, L'effet des niveaux de refroidissement (température de du moule) et des traitements Thermiques sur les propriétés mécaniques et sur la Microstructure des deux alliages composites Al-Si-Mg/SiC/10p, 1993 Université du Québec à Chicoutimi, Québec.

[9] D. J. Lloyd, E. Dewing, Stability of SiC in Molten Aluminum, in D. S. Wilkinson (Ed.) Advanced Structural Materials, 7178, Pergamon Press, New York 1989.

[10] A359 Al alloy reinforced with irregularly shaped $\mathrm{SiC}$ particles http://bricad.com/aluminium/dur/guides/awg/index.html. 